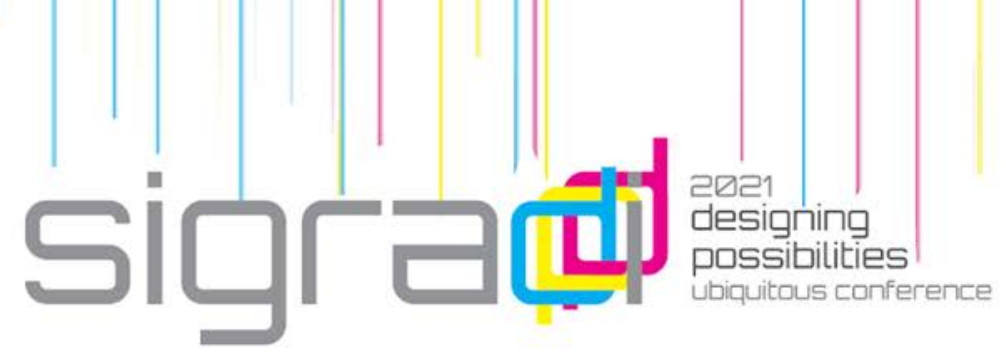

\title{
Design of Bio-Receptive Vertical Architectural Surfaces
}

\author{
Ramses Vladimir Salgado Melo ${ }^{1}$, Axel Becerra Santacruz ${ }^{1}$ \\ Maestría en Diseño Avanzado \\ ${ }^{1}$ Universidad Michoacana de San Nicolás de Hidalgo, México \\ ramses.vsm@gmail.com \\ axbesa03@gmail.com
}

\begin{abstract}
In the search for proposals and solutions related to the design of architectural envelopes, such as vertical gardens, there is data that shows that these strategies favor the improvement of the thermal capacity of these architectural skins (Oberndorfer et al., 2007). By means of passive strategies, this research aims to applied innovation in the development of a prototype of a bio-receptive surface that generates the favorable conditions for the proliferation development of vegetative agents, using concrete as a supporting base and modifying their $\mathrm{pH}$ levels with the objective of generating a balance for the proliferation of bryophytes. Through iterative experimental processes, a relationship between shape, surface and material composition is sought to generate a surface that produces bio-receptivity conditions.
\end{abstract}

Keywords: Responsiveness, bio-receptivity, variability, colonization, bryophytes.

\section{Introducción}

Se tiene registro de que el uso de vegetación en fachadas ayuda a mejorar las condiciones de aislamiento hacia el interior de una edificación. Según Köhler (Oberndorfer et al., 2007) en un estudio realizado en Berlín, Alemania, en invierno, las plantas de tipo enredadera denominados 'escaladores jóvenes' ayudan a generar una diferencia de temperatura de $+3^{\circ} \mathrm{C}$ en el interior de una edificación con respecto a la temperatura del exterior, esto registrado en el monitoreo de las noches más frías registradas en dicha temporada, que pueden llegar a los $-2^{\circ} \mathrm{C}$ en promedio y en verano hasta $-3^{\circ} \mathrm{C}$ en el interior (a la sombra), con respecto a la temperatura exterior que puede llegar a los $24^{\circ} \mathrm{C}$ con un $25 \%$ de pérdida de calor para una fachada. 


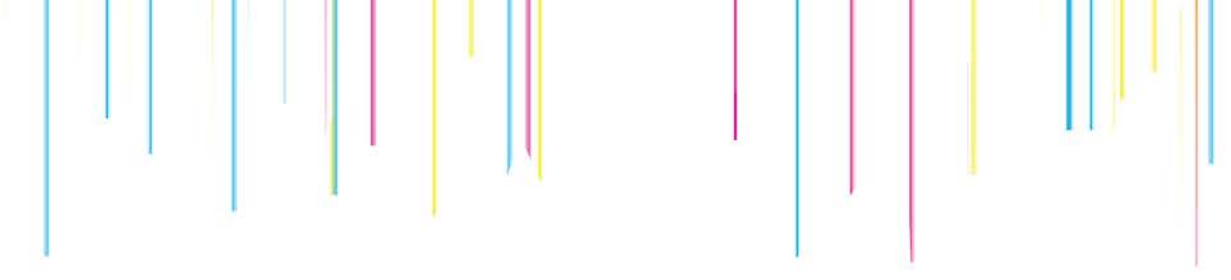

Los edificios cambian el flujo de energía y materia a través de los ecosistemas urbanos, a menudo causando problemas ambientales. Estos pueden mitigarse parcialmente mediante la alteración de las propiedades superficiales de los edificios. La adición de vegetación puede disminuir varios efectos negativos de los edificios en los ecosistemas locales y puede reducir el consumo de energía de los edificios (Oberndorfer et al., 2007).

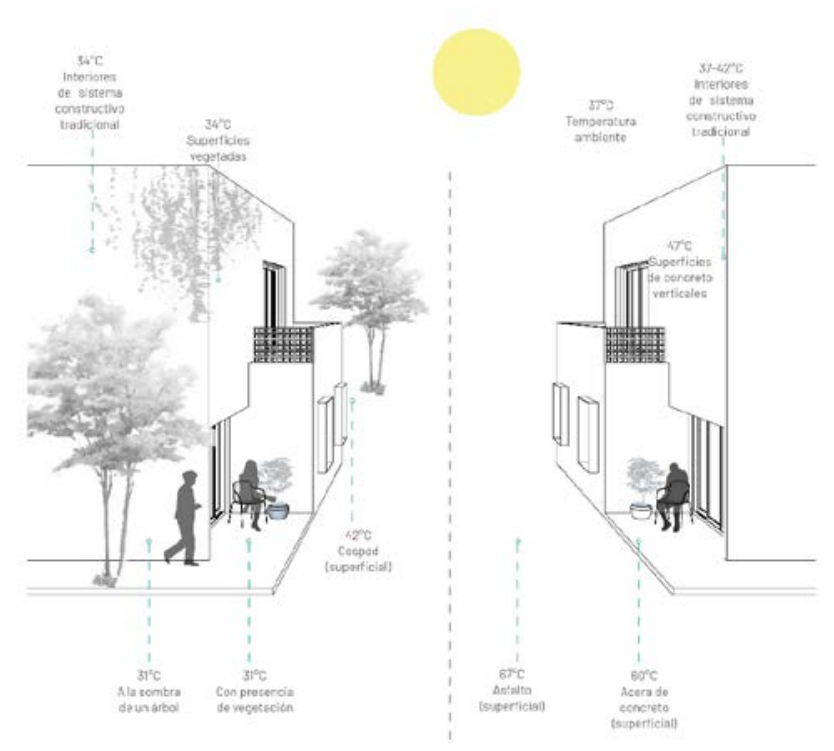

Figura 1. Diagrama de comparación de la temperatura con y sin implementación de vegetación en su arquitectura (Elaboración propia).

Se les denomina fachadas vegetativas a los sistemas de envolventes arquitectónicas que utilizan plantas, normalmente de tamaño reducido y con la capacidad de poder crecer de manera horizontal. Las más utilizadas son las plantas tapizantes. En general se subdividen en dos clases: muros vivos y fachadas vegetales. Los muros vivos tienen como principal característica el que las especies vegetativas se asocien con las estructuras de las fachadas componiendo una sola estructura. Las fachadas vegetales son estructuras en donde el sustrato de las plantas se encuentra en la misma disposición vertical de una fachada sin estar asociada con esta, sostenida mediante una estructura adosada (Grujic, 2011).

En la investigación de especies vegetativas, para su implementación en el desarrollo de fachadas vegetativas, se ha propuesto la implementación de las briofitas. Las briofitas o comúnmente conocidas como musgos son plantas verdes, generalmente pequeñas, miden desde unos milímetros hasta 20-30 


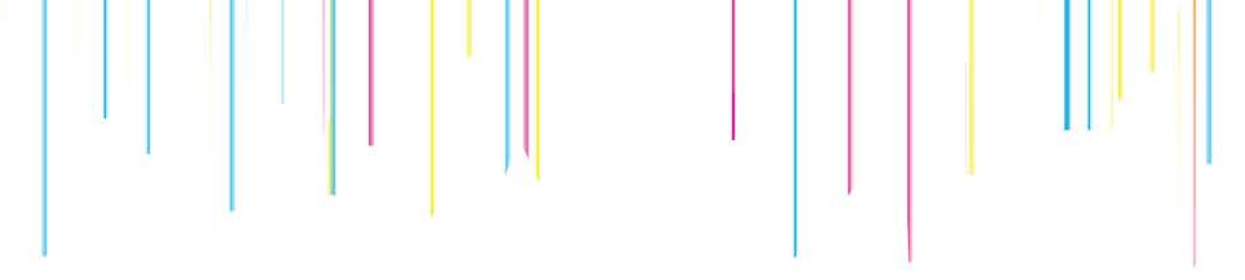

$\mathrm{cm}$, aunque en algunas formas erectas o con tallos colgantes, alcanzan en ocasiones casi 1 metro. Viven sobre el suelo, rocas o flotado en agua dulce (Delgadillo-Moya, 2014).

Por sus características, generan interés en el campo de estudio de la fabricación de concretos bio-receptivos, ya que no requieren de gran mantenimiento, crecen de manera aleatoria en superficies donde se generan las condiciones adecuadas de humedad y asoleamiento necesarias para obtener sus nutrientes. Sus bases portantes pueden llegar a ser muros de diversos materiales en donde crecen de manera aleatoria. Esto abre un campo de investigación para su implementación en los envolventes arquitectónicos.

Ante la propuesta de generar un acercamiento entre el control de la materia viva y su proliferación en ciertos materiales propensos a ser colonizables, se pueden aprovechar dichas propiedades para su integración en nuestro ambiente construido, por medio del diseño de superficies, de uso común en la construcción.

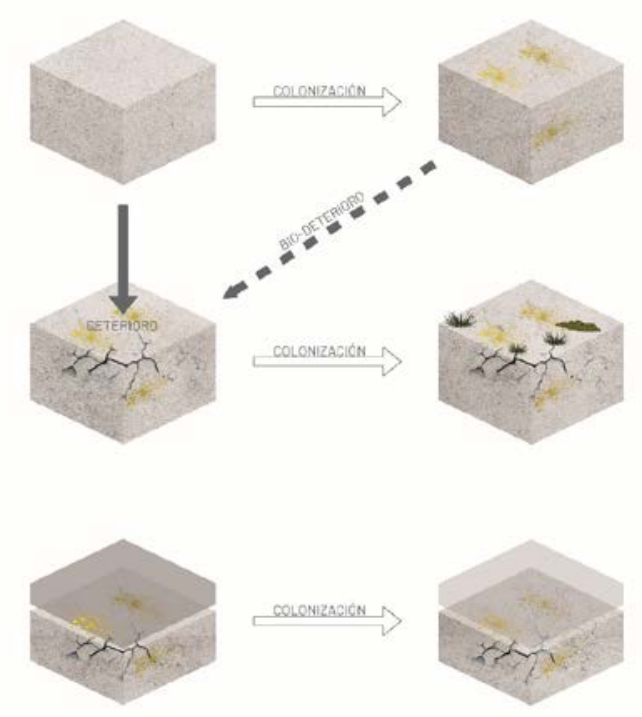

Figura 2. Bio-receptividad primaria, secundaria y terciaria en un material pedregoso. Flechas blancas, flechas negras y líneas discontinuas representan los mecanismos de colonización, deterioro físico-químico y bio-deterioro, respectivamente (Elaboración propia basada en el diagrama de bio-recepividad de Guillitte, 1995).

Guillitte define la bio-receptividad como la capacidad de un material de ser colonizado por organismos vivos. Define varios niveles de bio-receptividad: primaria, secundaria y terciaria. La bio-receptividad también se puede definir 


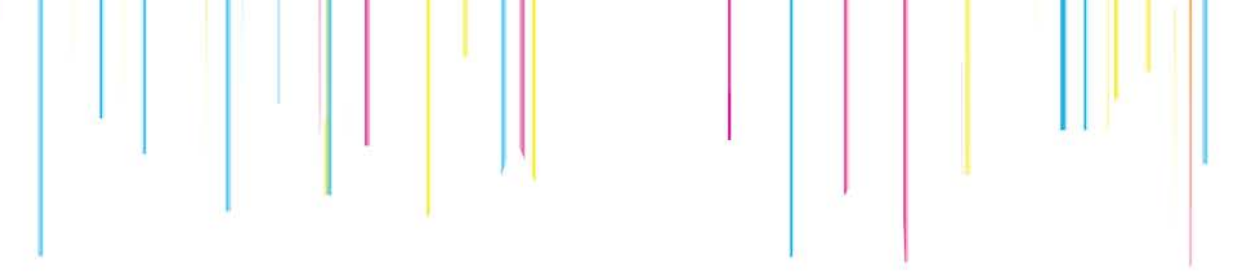

como la totalidad de las propiedades materiales que contribuyen al establecimiento, anclaje y desarrollo de fauna y / o flora. En materiales rocosos, se relaciona con las propiedades del área expuesta a la intemperie, como rugosidad, porosidad, humedad y la composición química de la capa superficial.

Se le denomina bio-receptividad 'nula' al estado de un material de no exhibir signos de colonización (que no alberga o desarrolla organismos biológicos). Se le denomina bio-receptividad 'primaria' cuando se da la primera aparición de un organismo colonizador (ya sea musgo, liquen u otro tipo de organismo vivo), sobre la superficie o en el interior de dicho material, esto siempre y cuando sus propiedades sigan siendo muy similares o idénticas a las de su estado inicial (Guillitte, 1995).

La característica de estas propiedades puede evolucionar con el tiempo bajo la acción de organismos colonizadores u otros factores que provocan cambios en dicho material y dan como resultado un nuevo tipo de bioreceptividad, que llamaremos bio-receptividad secundaria. La bio-receptividad secundaria suele ser más importante que la bio-receptividad primaria. Cualquier actividad humana que afecte la consolidación del material ya sea en su superficie o en su interior, si se recubre con algún agente que potencie la colonización, o modifique su superficie en cuestión de textura, puede inducir en la aceleración o la disminución del proceso de colonización primaria y secundaria(Guillitte, 1995).

\section{Metodología}

Como parte del proceso de diseño de una propuesta de envolvente arquitectónica que implemente la integración entre sistemas biológicos y artificiales, se partió de la investigación y recopilación de casos análogos donde se proponen dichas estrategias. En el análisis y síntesis de la información se optó por el estudio y profundización de las condiciones en las cuales los musgos se desarrollan de manera espontánea y controlada en ambientes artificiales.

Como parte del proceso de diseño se realizan exploraciones analógicas y digitales donde ambos procesos se retroalimentan entre sí para llevar a cabo los ajustes pertinentes durante un proceso iterativo que retoma procesos creativos experimentales y metodologías de diseño como: Metodología 


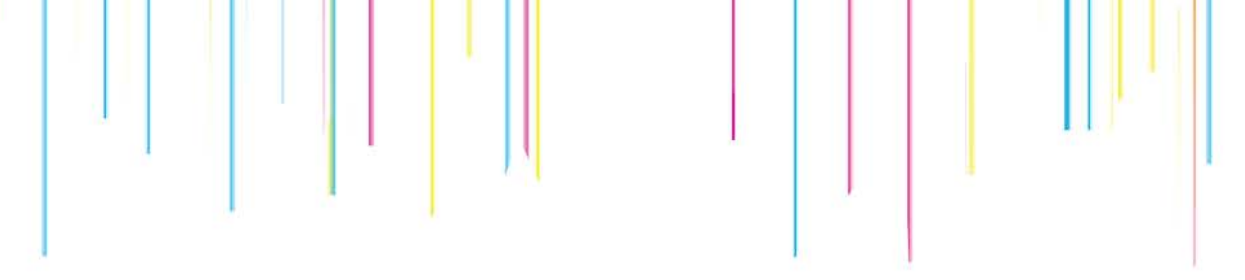

Proyectual (Munari, 1983) y Design Thinking (Design Thinking en Español, n.d.).

La investigación se centra en la clase briofita que reúne ciertas características como el uso mínimo de sustrato y que sobrevive sobre superficies artificiales. Se selecciona una especie en particular, la cual se encuentra en nuestro contexto inmediato (Morelia, México). Para la generación de niveles de colonización sobre un material utilizado en la arquitectura se determina como indicador los niveles partículas de Hidrógeno $(\mathrm{pH})$ adecuados para la proliferación de dicha especie vegetativa en una superficie de concreto como base portante vertical. Es por esto que, siendo el concreto uno de los materiales más utilizados en nuestro contexto inmediato, se opta por realizar modificaciones en los elementos compositivos de los distintos agregados, introduciendo elementos que puedan generar mezclas a menos alcalinas y favorezca la creación de niveles adecuados de bio-receptividad.

Mediante el diseño paramétrico se realizan exploraciones digitales, basadas en el estudio de la morfología de las bases portantes que permiten el crecimiento y la proliferación de las briofitas. Posteriormente, por medio de la tecnología de fabricación aditiva, se fabrican una serie de moldes para la producción de dichas bases artificiales.

La propuesta tiene como objetivo crear la posibilidad de colonización de una superficie vertical arquitectónica, compuesta por una materialidad específica, que contenga los elementos idóneos para generar niveles de bio-receptividad, principalmente la bio-receptividad primara.

Para la comprobación de la alteración de los niveles de $\mathrm{pH}$ de concreto que conforma las bases portantes se realizan las mediciones de muestras, tanto de los agregados como de las mezclas finales de concreto, cada una de las pruebas por medio de sustancias como la antocianina como indicador cromático, presente de manera natural en algunas especies de plantas.

Mediante procesos análogos y de tecnología de fabricación aditiva, se producen los prototipos finales que responde a la información recabada anteriormente.

\subsection{Selección de Especie Vegetativa}

La importancia de los briófitos no es solamente evolutiva: se trata del segundo grupo de plantas te-rrestres más diversificado (muy por delante de las 


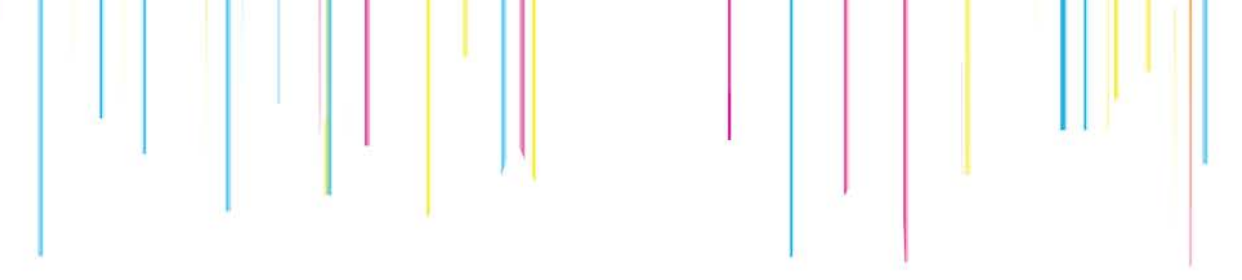

gimnospermas y de los pteridófitos), y aunque raramente dominan en cuanto a biomasa los ecosistemas, juegan un papel estabilizador creciente-mente reconocido (Estébanez Pérez et al., 2011).

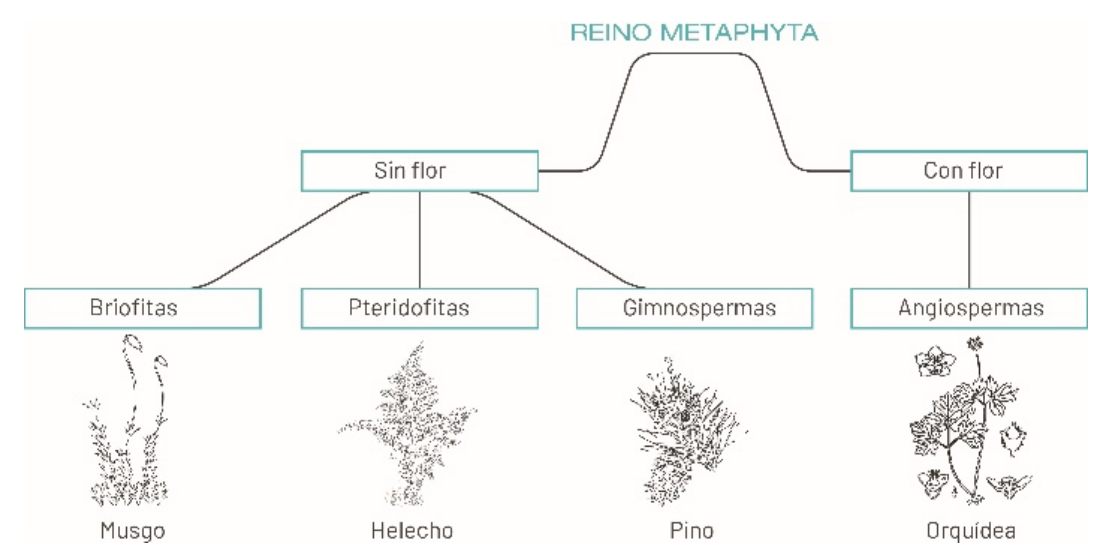

Figura 3. Diagrama de Phylums del reino Metaphyta (Elaboración propia basada en el diagrama de la clasificación de los briofitos, Estébanez Pérez et al., 2011).

Las briofitas pertenecen al grupo de las plantas terrestres no vasculares; son plantas que carecen de tejido vascular que transporta agua, minerales y nutrientes hacia todas las partes del organismo. Poseen 3 divisiones: Marchantiophyta (hepáticas), Anthocerotophyta (antocerotófitos) y Bryophyte (musgos). En sentido estricto, las briofitas son los musgos, pero en su sentido amplio la palabra designa a dichas divisiones. Las briofitas más comunes son los musgos y las hepáticas, aunque son más conocidos los primeros. En Michoacán se tiene un registro de al menos de 452 especies de briofitas registradas ante el segundo Estudio de Estado, por parte del Instituto de Investigaciones sobre los Recursos Naturales, UMSNH (Isela Edith Zermeño Hernández, Ireri Suazo Ortuño, 2020).

En el caso particular de la zona urbana de Morelia, la diversidad, cobertura, frecuencias y vitalidad de las poblaciones de musgos y líquenes epifitos se han visto afectadas negativamente por el deterioro de la vegetación y las diferentes emisiones de contaminantes (Morón et al., 2014). En zonas urbanas de Morelia, se han identificado en espesuras, principalmente en la zona oriente, donde se identifica su biomasa principalmente sobre las cortezas de árboles como el Oyamel, el Pinus y Quercus (Verdes et al., 2017).

Mediante un análisis morfológico y con el análisis taxonómico recabado, se pudo hallar una variedad de la especie, identificada como Polytrichum commune (UNAM,2020). 

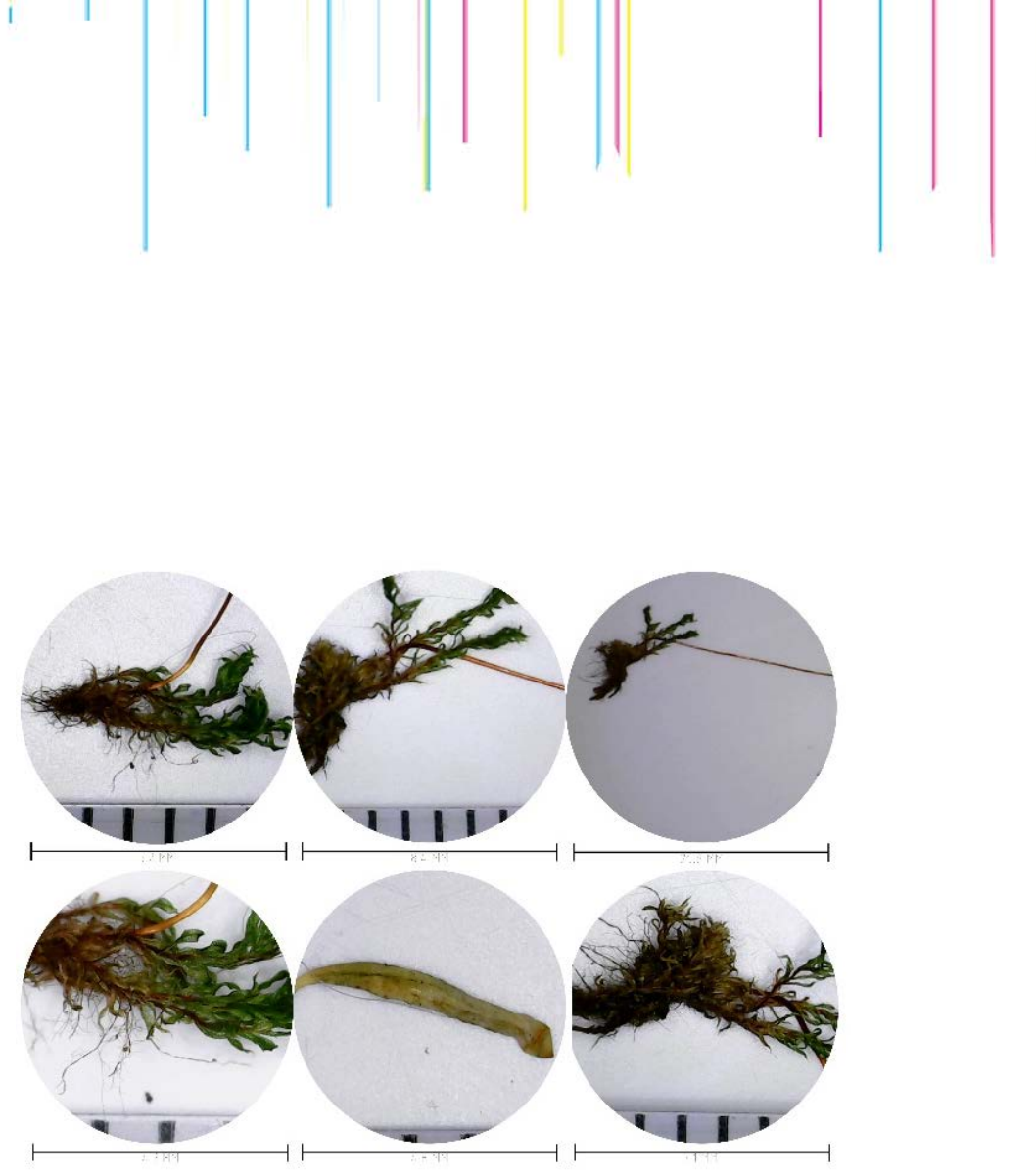

Figura 4. Imágenes microscópicas de la especie briofita Polytrichum Commune (Elaboración propia).

Ficha Briológica polytrichum commune, Reino: Plantae, Phylum o división: Bryophyta, Clase: Bryopsida, Orden: Polytrichales, Familia: Polytrichaceae, Género: Polytrichum, Especie: Polytrichum commune, Nombre científico: Polytrichum commune, Determinador (es): Manuel González (UNAM,2020).

\subsection{Indicadores de pH-MAB}

En el desarrollo del material portante, el cual estará denominado como (MAB), se busca modificar algunas de las propiedades del concreto convencional, esto con el objetivo de desarrollar ciertas condicionantes que nos permitan la colonización de la misma.

El concreto generalmente cuenta con valores de $\mathrm{pH}$ de 12 y 13 . Esto se debe a que debe generar un ambiente alcalino para evitar así la corrosión del acero de refuerzo (Cemento - CEMEX, n.d.). 


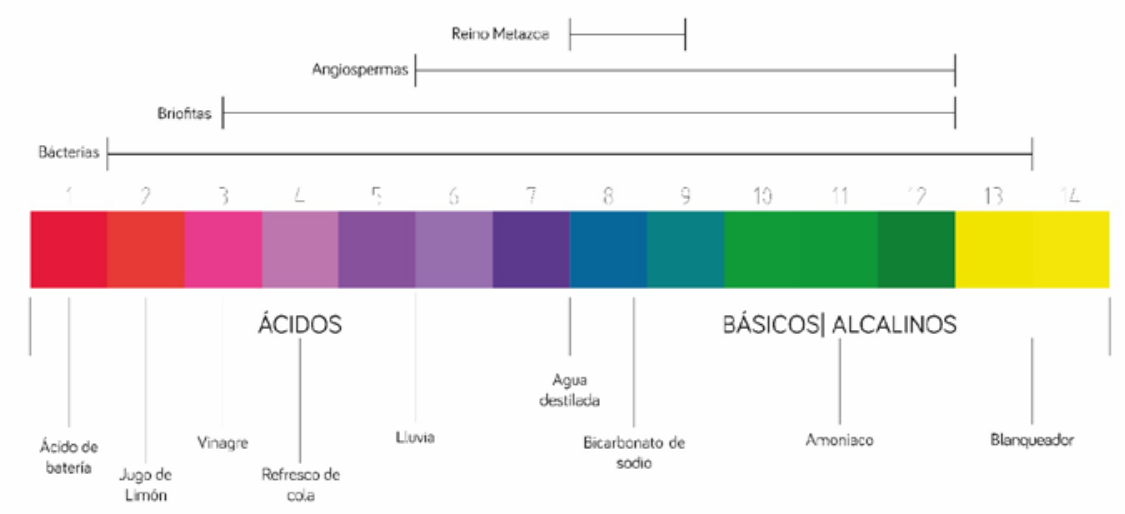

Figura 5. Colorimetría de $\mathrm{pH}$ para análisis con antocianinas, y comparativa de $\mathrm{pH}$ en organismos vivos y sustancias químicas ( Elaboración propia basado en diagrama de Contreras \& Rojas, 2014).

\subsection{Experimentación pH}

Se realiza la siguiente prueba, con 2 muestras materiales minerales naturales, y una que es producto del residuo natural, en este caso se toma el residuo del molido del café por sus propiedades granulares y ácidas, esto para equilibrar el pH del MAB final. Indicador: Reacción de la coloración de la Antocianina.

Ingredientes:

- Antocianina extraída de Col morada/ lombarda.

- Cloruro de sodio (Sal granulada)

- Tepetate

- Sedimento de café 'borra'.

Desarrollo: Colocando ahora 3 recipientes con $100 \mathrm{ml}$ del compuesto de la antocianina. En este caso las soluciones son cloruro de sodio con un $\mathrm{pH}$ de 7 , se somete a pruebe un agregado mineral denominado comúnmente como tepetate y se introduce la borra de café en otro recipiente, esto como un elemento de origen vegetal y de residuo, se decanta esta opción al ser un producto de consumo común y diversificado a nivel global, pero no exclusivamente podría ser este producto. El uso de cualquier otro material de origen vegetal con ciertas características podría ser utilizado en la modificación del $\mathrm{pH}$, mientras que no afecte las condiciones de resistencia del concreto. Una vez obtenidos los resultados se hace la comparativa de las mezclas obtenidas con la escala gráfica de $\mathrm{pH}$ para la antocianina. 

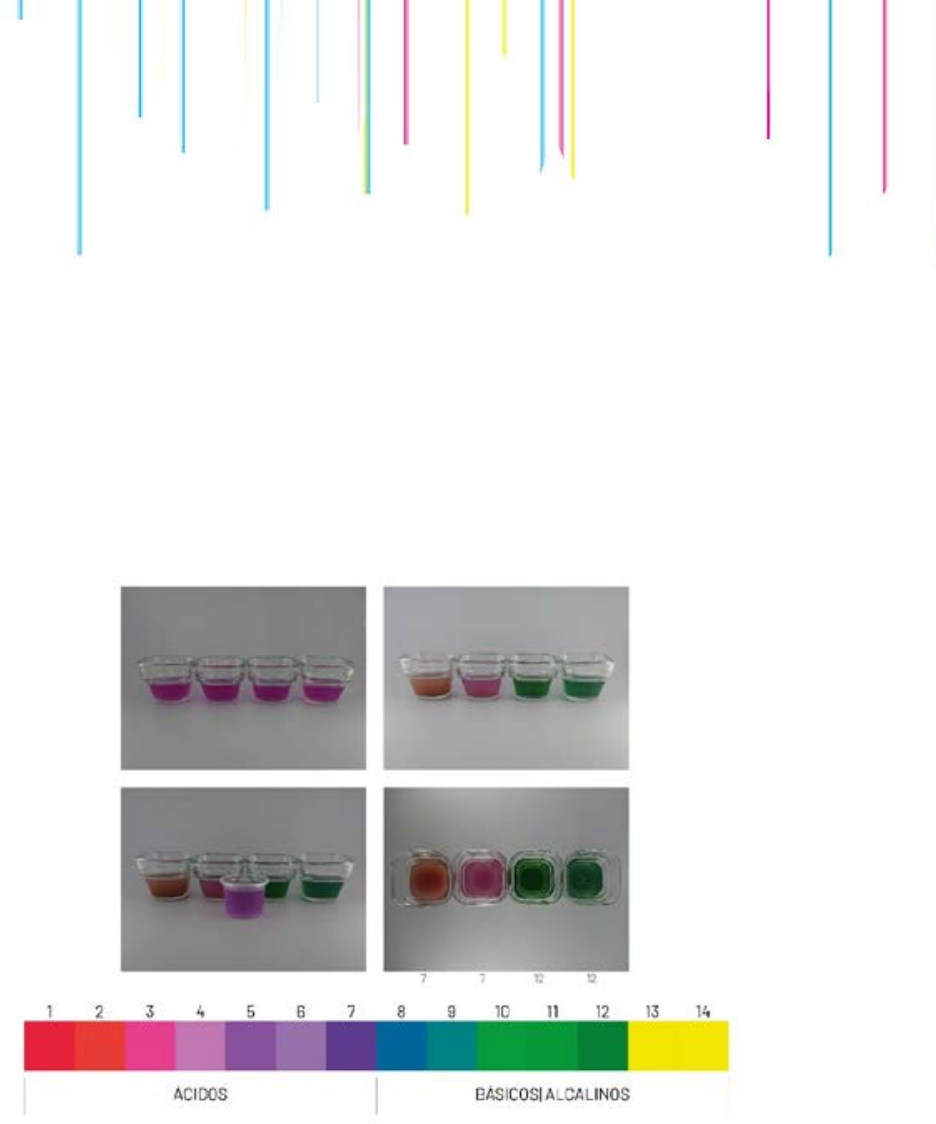

Figura 6. Comparativas del antes y el después de las diferentes sustancias reaccionando al indicador de antocianina. comparativas con el testigo neutro (Elaboración propia).

\subsection{Prueba MAB + pH}

Al tomar una pieza de $10 \mathrm{gr}$ de cada una de las muestras finales MAB-03-T3 y MAB-03-C1, se sumergen en dos cups de cristal con $50 \mathrm{ml}$ de antocianina previamente preparada. De deja reposar las muestras para su reacción alrededor de 72 hrs.

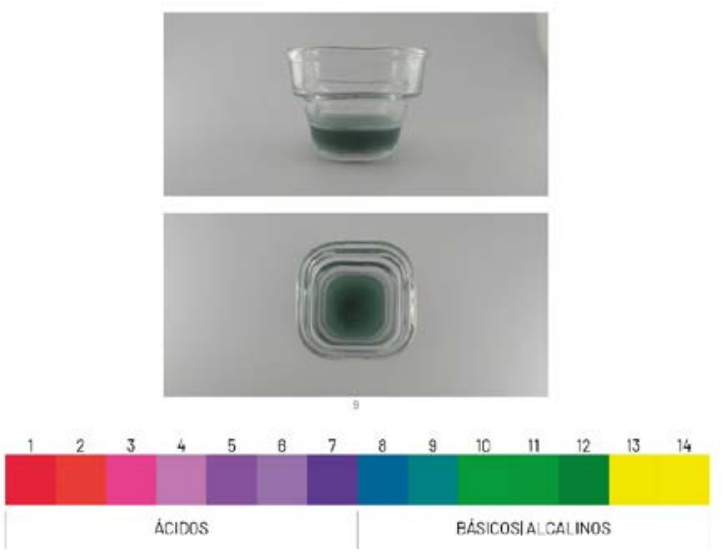

Figura 7. Resultados de colocación de 10gr de muestra MAB-03-T3 y C1, Izq. y der. respectivamente, en prueba de indicador de $\mathrm{pH}$ (Elaboración propia). 


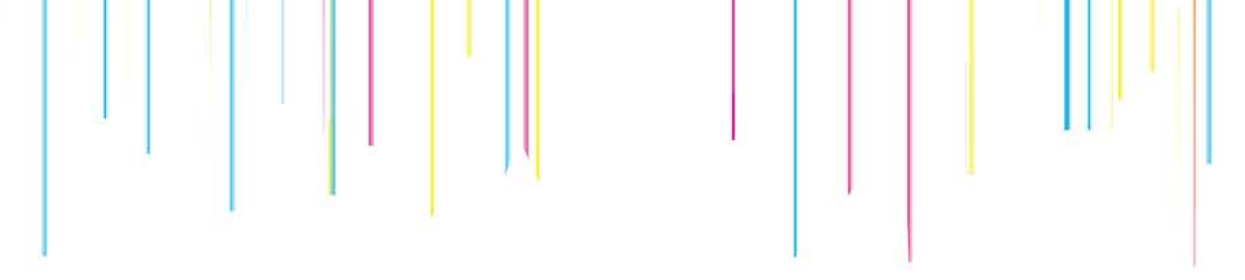

\section{$3 \quad$ Resultados}

Conclusiones: El cambio de coloración como lo muestra en las imágenes da resultados alcalinos, sin haber variación en la muestra de tepetate MAB-03-T3 en comparación a la coloración del cemento ( $\mathrm{pH}$ entre 12 y 13). Caso contrario en la muestra de pieza la MAB-03-C1, la cual resulta con modificaciones en sus $\mathrm{pH}$ visibles en el cambio de coloración dando como resultado en la escala gráfica de $\mathrm{pH}$ valores aproximados al 9 . Podemos concluir que nos arroja un dato satisfactorio ya que, al alterar los niveles de $\mathrm{pH}$ de una mezcla de concreto, podemos acercarnos a niveles de bio-receptividad a nivel material.

El cambio de coloración como lo muestra en las imágenes da resultados alcalinos, sin haber variación en la muestra de tepetate MAB-03-T3 en comparación a la coloración del cemento (pH entre 12 y 13). Caso contrario en la muestra de pieza la MAB-03-C1,

\subsection{Exploración SPF}

La propuesta de exploración de la modificación de una superficie, basada en un script, se basa en el análisis de la lógica de las estrategias de crecimiento de los entes vivos y su crecimiento en las superficies, con el objetivo de poder recrear hasta emular las superficies naturales, mediante el control de la variabilidad de la morfología.

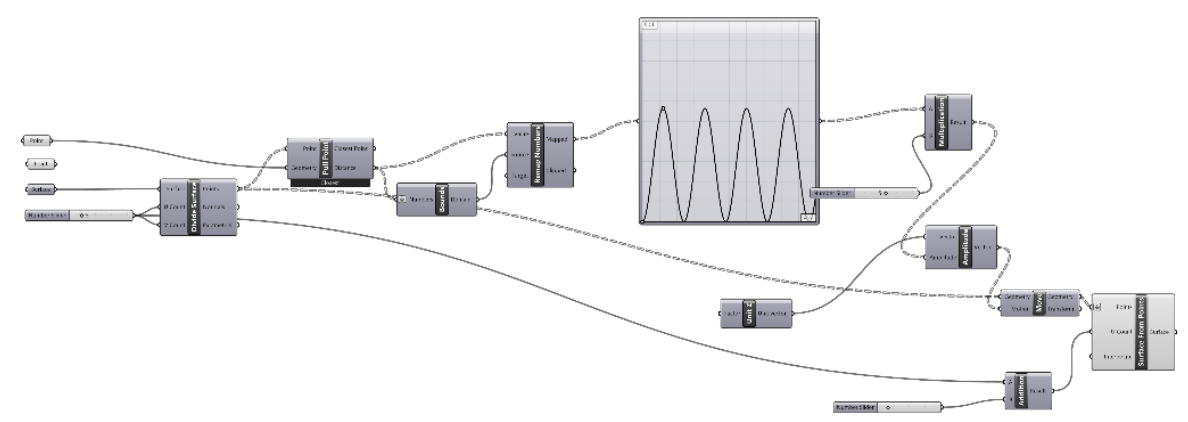

Figura 8. Definición algorítmica. Rhinoceros + Grasshopper1.001. 

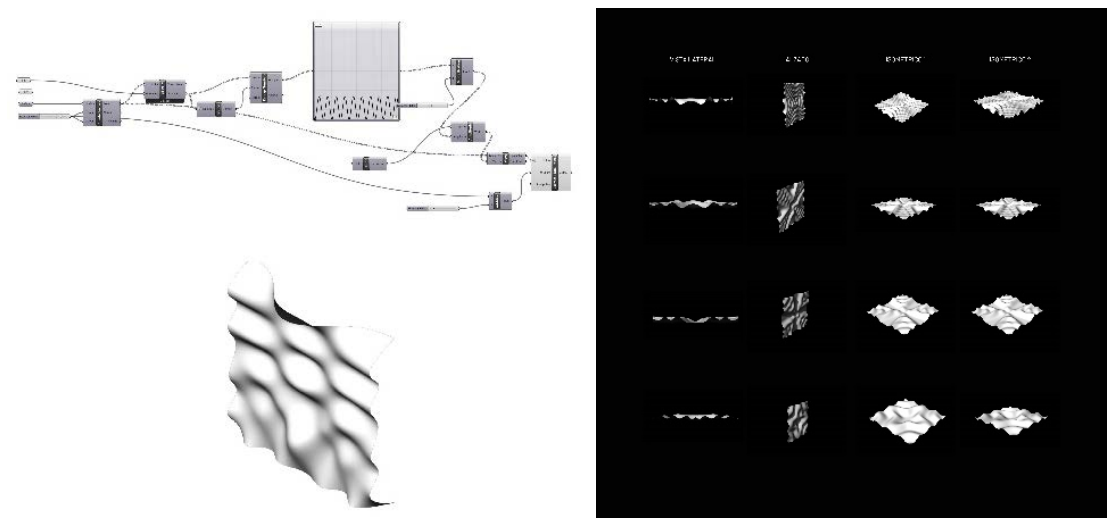

Figura 9. Exploración morfológica digital de prototipo SPF. Rhinoceros + Grasshopper1.001. Figura 10. Definición algorítmica. Rhinoceros + Grasshopper1.001 (Elaboración propia).

Objetivo principal de esta exploración es el control de la variabilidad mediante el uso del diseño paramétrico digital.

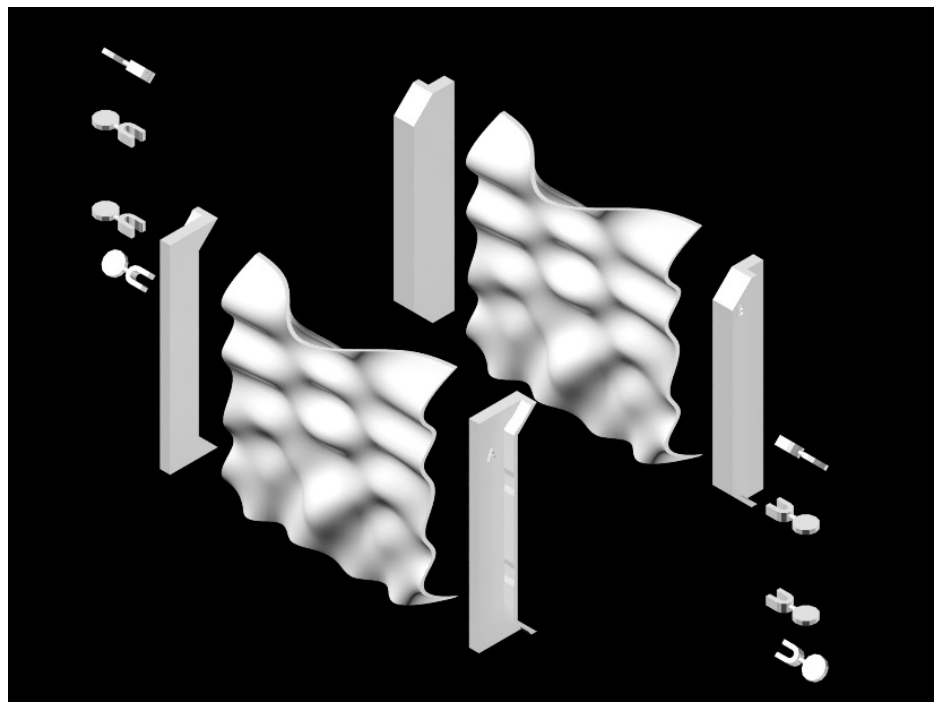

Figura 11. Modelo digital de despiece de molde (Elaboración propia).

En el proceso de generación de molde de la pieza final de concreto, con mezcla portante MAB-03, se obtienen resultados satisfactorios después de la segunda prueba. 
para el diseño. Ya que las lógicas de sobre posición de material en capas, están basadas en estrategias presentes en la naturaleza y que responde a lógicas de crecimiento biológico (Taller Impresión Robótica - SIGraDi2020, n.d.). A través de la generación de los moldes para el diseño de nuestra pieza SPF, nos permitió observar que en el proceso de su impresión se generaron 0 (cero) soportes para su fabricación.

Con respecto a los objetivos establecidos, se logra realizar alteraciones en las mezclas de concreto y establece ciertos parámetros para la realización de futuras pruebas donde se pueda perfeccionar la composición del material como base portante. El siguiente paso consistirá en la conjunción de los elementos vegetativos y los elementos artificiales, estableciendo los protocolos necesarios para la evaluación de los resultados de tales experimentos.

El pensar en otras escalas y la manera en cómo podemos simplificar procesos, tal como se hizo en la fabricación e impresión de moldes, se concluye que es pertinente, seguir trabajando en el manejo de dichas herramientas de fabricación, que paulatinamente se encuentran más a nuestro alcance. Con esto no se trata de reducir nuestro abanico de opciones a un solo tipo de tecnología de fabricación digital-material, pero nos ayuda dar dirección de hacia dónde podría llegar nuestro trabajo de investigación en proyectos futuros.

\section{Referencias}

Cemento - CEMEX. (n.d.). Retrieved January 18, 2021, from https://www.cemex.com/es/productos-servicios/productos/cemento

Contreras, E., \& Rojas, G. (2014). pH Folleto Inf. 3-7.

Delgadillo-Moya, C. (2014). Biodiversidad de Bryophyta (musgos) en México. Revista Mexicana de Biodiversidad, 85(SUPPL.). https://doi.org/10.7550/rmb.30953

Design Thinking en Español. (n.d.). Retrieved April 20, 2020, from http://www.designthinking.es/inicio/

Estébanez Pérez, B., Draper y Díaz de Atauri, I., \& Medina Bujalance, R. (2011). Briofitos: una aproximacion a las plantas terrestres más sencillas. Bryophytes: An Approximation to the Simplest Land Plants., 9(January), 19-73.

Grujic, J. (2011). Arquitectura vegetada: funcionalidades de la vegetación en 
el metabolismo del edificio.

Guillitte, O. (1995). Bioreceptivity: a new concept for building ecology studies. Science of the Total Environment, 167(1-3), 215-220. https://doi.org/10.1016/0048-9697(95)04582-L

Isela Edith Zermeño Hernández , Ireri Suazo Ortuño. (2020). 15610.

La, M. D. E., \& Hurtado, M. (2016). TITULO PRIMERO Disposiciones Generales CAPITULO UNICO. 1-268.

Morales, C., Ospino, J., Jiménez, J., Berbén, A., \& Negritto, M. (2017). Briófitos: Un Mundo En Miniatura. INFOFLORA Boletín de Botánica, 1, 12. http://www.corantioquia.gov.co/ciadoc/FLORA/AIRNR_CN_7567_2007. pdf

Munari, B. (1983). Cómo nacen los objetos.

Nociones básicas de taxonomía vegetal - Angel Marzocca - Google Libros. (n.d.). Retrieved January 23, 2021, from https://books.google.com.mx/books?hl=es\&lr=\&id=hhZOSDbSdegC\&oi= fnd\&pg=PA255\&dq=carlos+linneo+taxonomia\&ots=jZ625wgVJ4\&sig=pV M87IOeM1Hw4_vh75Qrw1RVkJw\#v=onepage\&q=carlos linneo taxonomia\& $f=f a l s e$

Oberndorfer, E., Lundholm, J., Bass, B., Coffman, R. R., Doshi, H., Dunnett, N., Gaffin, S., Köhler, M., Liu, K. K. Y., \& Rowe, B. (2007). Green roofs as urban ecosystems: Ecological structures, functions, and services. BioScience, 57(10), 823-833. https://doi.org/10.1641/B571005

Taller Impresión Robótica - SIGraDi2020. (n.d.). Retrieved February 24, 2021, from https://sigradi2020.upb.edu.co/talleres/taller-impresion-robotica/ 